\title{
THE ART OF SIMULATION MODELLING
}

\author{
P.S. Kruger \\ Department of Industrial and Systems Engineering \\ University of Pretoria \\ paul.kruger@eng.up.ac.za
}

\begin{abstract}
It is the contention of the author that practising the "art" of modelling has been, and always will be, of great importance to the ultimate success of any project employing a simulation approach. Yet very few publications address this aspect of simulation modelling exclusively. This paper is an attempt to focus attention on some of these "softer" issues of simulation modelling. By using the concept of a Simulation Syndrome the paper endeavours to highlight some of these issues and to serve as a reminder to simulation modellers of some aspects of the "art" of modelling that are often taken for granted.
\end{abstract}

"Advice is seldom welcome; and those who want it the most always like it the least" Lord Chesterfield

\section{OPSOMMING}

Die outeur is van mening dat die "kuns" van modellering van groot belang is vir die uiteindelike sukses van enige projek waar gebruik gemaak word van 'n simulasiebenadering. Nietemin bestaan daar weinig publikasies waar hierdie aspek van simulasiemodellering spesifiek aangespreek word. Hierdie artikel is 'n poging om die aandag te vestig op sommige van die "sagter" aspekte van simulasiemodellering en die doelwit word bereik deur gebruik te maak van die konsep van 'n Simulasie-Sindroom. Op hierdie wyse word die gebruikers van simulasiemodellering herinner aan somminge aspekte van die "kuns" van modellering wat dikwels as vanselfsprekend aanvaar word.

"Advice is seldom welcome; and those who want it the most always like it the least" Lord Chesterfield 


\section{INTRODUCTION}

The science of simulation modelling has experienced significant development over the last three decades to a point where numerous sophisticated software tools are available, large and complex simulation models are being developed and used routinely by many companies and models employing virtual reality have become a reality [1]. In 1975 Robert E Shannon published a book, arguably still one of the best general books on simulation modelling, titled "Simulation Modelling : The Art and Science" [14]. Professor Shannon's book does contain some very valuable guidelines relating to the "art" of simulation modelling and most other textbooks on simulation modelling do make some comments on what is usually termed "good modelling practice" [9: p. 83 and p. 267, $6:$ p. 501]. Numerous published papers discuss modelling methodology or contain phrases such as "simulation is as much an art as a science" $[2,3,14,15]$. However, in general these papers tend to stress that which, in the author's opinion, may be classified as primarily the "science" of simulation modelling for example, the simulation process, problem definition, conceptual model formulation, data preparation, verification, validation and experimental design [15]. It seems as if relatively few papers have been published specifically addressing the "art" of simulation modelling. It is the contention of the author that practising the "art" of modelling has been, and always will be, of great importance to the ultimate success of any project employing a simulation approach. Furthermore, the rapid and continuing advances made in the science of simulation modelling place an even greater emphasis on good modelling practice.

This paper is an attempt to focus attention on some of the "softer" issues of simulation modelling and is based primarily on the author's own limited experience and possibly superstitions garnered and gathered over several years.

\section{SETTING THE SCENE}

The present may be seen as the fleeting transition between the known, but problematic past and the uncertain, but wonderful future. The present generation will never resist the temptation to dispense unsolicited advice to future generations, especially warnings about the dangers lurking in the future, based on past experience of doubtful value and applicability. This well-meant advice will, in all probability, never be heeded by anyone, in the same way in which the observations made during the "warm-up period" of a simulation run are discarded forever, but nevertheless serve a purpose.

Nonetheless, this paper will consist of nothing but such advice, admonishments, warnings and cautions, about the art of simulation modelling. The main purpose of this paper is therefore to try and remind practitioners of the art of simulation modelling, since this is, similar to good table manners, often taken for granted. This may be achieved by identifying and briefly discussing some of the seven(ty) deadly sins of simulation modelling in a somewhat lighthearted, but not necessarily frivolous manner.

In Christian tradition, and listed with minor variation by the monk John Cassian, St Gregory the Great and St Thomas Aquinas, the Seven Human Vices consist of Pride, Covetousness, Lust, Envy, Gluttony, Anger and Sloth [5, 10]. Conversely, the Seven Human Virtues are proclaimed to be Faith, Hope, Charity, Justice, Fortitude, Prudence and Temperance [7]. This paper will attempt to identify some of the virtues and vices associated with simulation 
modelling. However, since the words "virtues and vices" contain inherent connotations of "good and bad" (one person's vice is often another person's virtue, and vice versa), the comparative neutral concept of Simulation Syndromes will be used.

The main thrust of this paper is therefore to identify and discuss, in a relative cryptic fashion, a number of these "simulation syndromes". Though the paper is mainly intended to serve as a checklist for the inexperienced modeller, the experienced modeller may find it useful as an occasional reminder.

Simulation modelling consists of a variety of seemingly disjointed concepts, techniques, approaches and technologies, for example artificial randomness, mathematical and statistical analysis, systems analysis and computer programming to mention but a few. The "art of simulation modelling" suffers from the same malaise and therefore the following "syndromes" may, in a similar fashion, seem to be somewhat unconnected. However, herein lies a significant part of the power and general applicability of simulation modelling and the challenge to link and integrate these "syndromes" into a wholesome whole is the unalienable privilege and responsibility of the modeller. Creating a perfunctory and rudimentary "Simulation for Dummies" guide is certainly not the author's intention.

"Rules and models destroy genius and art" William Hazlitt

\section{THE SIMULATION SYNDROMES ${ }^{1}$}

\subsection{The "44-Magnum" simulation syndrome}

"Make my day"

Clint Eastwood as Dirty Harry in the film Sudden Impact (1983)

Simulation modelling is a very powerful tool but therefore also a very dangerous one. If a powerful tool is misused, the consequences may be very bad, very sad or even catastrophic. Therefore, the proper use of such a powerful tool places a heavy responsibility on the shoulders of both model developer and user.

\subsection{The "Numbers are Magic" simulation syndrome}

$$
\begin{gathered}
\text { ".... if you can't count something, it doesn't count" } \\
\text { David Boyle }
\end{gathered}
$$

Life is teeming with numbers, and we are sometimes drowning in a sea of data. However, quantification by number is sometimes seen as the only acceptable approach. Simulation modelling is perhaps the primary technique through which it is extremely easy to generate large numbers of numbers. But, numbers do not have any vices or virtues, neither soul, feelings or conscience. They do not know the difference between right and wrong or good and evil. Numbers have no judgment, they simply do not care; numbers are only tools. There is,

\footnotetext{
${ }^{1}$ Syndrome a characteristic combination of opinions, emotions, behaviour, etc. [10]
} 
in the author's opinion, always some room for striking a balance between good judgment and good numbers.

\title{
3.3 The "Seeing is Believing" simulation syndrome
}

According to the ancient Greeks, one can never prove an assertion or a hypothesis by experimentation or observation alone. However, one may very easily disprove an assertion in this way. This philosophy is the very basis of modern day statistical inference. Therefore, one should give very careful consideration to the purpose of a model, the intended use of the model [2], the kind of answers required and how the simulation experiment should be designed and executed.

\subsection{The "Bigger is Better" simulation syndrome}

Simulation modelling is one of the few modelling techniques that allows for starting simple and subsequently to perform progressive enhancements to the model. However, expanding a model may not necessarily result in a more valid model and a more complex and bigger model may not necessarily be better. Furthermore, every enhancement is a potential source of nasty "bugs" and errors, which are often very difficult to trace and fix. It is the author's contention that many more models suffer from too much detail than suffering from not enough detail. An attempt should be made to keep the model as simple as possible and save oneself suffering from the Complexity Complex.

\subsection{The "Hole in the Doughnut" simulation syndrome}

Simulation modelling may be used to represent very large and complex systems in great detail, but a simulation model can never, ever, be the real world. Even the most detailed model will still display some small aberrations and deviations from the "real world" and these should not be blown out of proportion. An effort should be made to "create" some distance between the "creator" and the "creation" and to look at the "whole" rather than the "hole".

\subsection{The "It is my Child" simulation syndrome}

\author{
"So for the mother's sake the child was dear, \\ And dearer was the mother for the child" \\ Samuel Taylor Coleridge
}

Simulation modelling is a very creative, intensive and sometimes even enjoyable exercise. The "father or mother" of the model should be careful not be blind to the "child's" shortcomings. These deficiencies should be recognized, accepted and the modeller should live with them as best as possible. However, similar to a child, the modeller should take time to know his or her model, spend some quality time with it, play with it, observe it, take it for lunch, and even take it for a trip.

\subsection{The "Uncertainty Paralysis" simulation syndrome}

No simulation model can ever be made perfect in one lifetime. There will always remain some uncertainty about the validity of the model and thus the validity of the output. This 
uncertainty should not be allowed to have a paralysing effect; rather accept the responsibility for making decisions based on a somewhat less than perfect model. The risk of giving the "wrong" answer should be balanced against the possible gain of at least providing "some reasonable useful answer".

\title{
3.8 The "People are Rational" simulation syndrome
}

\author{
"With men he can be rational and unaffected, \\ but when he has ladies to please, every feature works" \\ Jane Austen
}

Building a simulation model requires the existence of a set of very exact system operating rules, but human behaviour is inevitably an inherent part of most systems and people do not act rational. The relatively unpredictable actions of people are often one of the major sources of variation in a model. However, the model may be used to define the range of acceptable human behaviour and to highlight the consequences of deviating from the assumed operating rules.

\subsection{The "Sexy Software" simulation syndrome}

The simulation software may be able to provide all the necessary "bells and whistles" to create a 3D-animation, or virtual reality tour, of the system. A bright-eyed, bushy-tailed young Industrial Engineer, or even worse, a pushy consultant may display this with much fervour, which may lead to an unjustifiable good impression. Meanwhile, a less complex model may provide much better results. Similarly, the transient infant hype of new software or techniques should be regarded with at least some trepidation.

\subsection{The "Self Fulfilling Prophesy" simulation syndrome}

A simulation model should provide, in general terms, the expected answers. However, a model may sometimes be manipulated to do precisely that and with a little effort a model may be used to prove just about anything on demand. Pressures from the boss, peers or clients to support their pet theories or to validate poor decisions that may have already been made should be resisted and repressed. The modeller should try to keep his modelling integrity intact. Furthermore, a simulation model may easily be similar to a "magic mirror" in the sense that the modeller may tend to see only what he or she wants to see.

\subsection{The "Beauty is in the Eye of the Beholder" simulation syndrome}

\section{"Competence, like truth, beauty and contact lenses, is in the eye of the beholder" Laurence Peter}

Efficient simulation modelling is as much an art as a science. An activity requiring a measure of artistic talent, or at least some imagination, is often not easily amiable to tight schedules and deadlines. Accurately estimating project time duration and resource requirements may be rather difficult. Dividing the project into several phases should be considered and very clear and practically useful deliverables should be defined for each phase. 


\title{
3.12 The "Structure in Chaos" simulation syndrome
}

The world and the systems in it, natural and man-made, often seems to be totally unstable, in a state of disorder and chaos with infinite complexity, never reaching any kind of steady state. However, there is some structure, some pattern, some order, and some predictability in even the most chaotic of complex systems. It is the responsibility of the modeller to recognize, identify, extract and abstract the essence of this structure and to model it effectively.

\subsection{The "Terrific Toolbox" simulation syndrome}

"Man is a tool-using animal ...

Without tools he is nothing, with tools he is all"

Thomas Carlyle

Simulation modelling in practice may be seen as an arsenal of tools, approaches and techniques, i.e. a terrific toolbox. Choosing the appropriate approach is very important, but the major challenge and prerequisite is to have an intimate and updated knowledge of the contents of the "toolbox", for example the specific and sometimes peculiar characteristics of the simulation software being used.

\subsection{The "I need ALL the Data" simulation syndrome}

\author{
"Where is the Life we have lost in living? \\ Where is the wisdom we have lost in knowledge? \\ Where is the knowledge we have lost in information?" \\ T. S. Eliot
}

Obtaining all the data and information, of an infinite accuracy and precision, is a prerequisite for building the perfect model of a perfect world in an infinite amount of time ! Fortunately simulation modellers are mortal human beings, they are not in the business of building perfect models and are suppose to live in the real world. If at all possible a proto-type, "first swipe" model should be used, and appropriate sensitivity analysis performed to guide the data gathering effort.

\subsection{The "Singularities at the Edge of the Universe" simulation syndrome}

The inherent structure of simulation models is often such that one may use the model to visit the distant, unexplored, possibly very strange corners of the modelling universe, safely and at little extra cost. This may not only provide valuable insights into the unknown intrinsic characteristics of the system being modelled but may be priceless for purposes of model verification and validation. In essence, consider driving the model to its extremities and observe whether it still provides reasonable and acceptable answers.

\subsection{The "Baloney Detection Kit" simulation syndrome [12]}

One should endeavour to confirm independently the so-called "facts", provided by so-called "authorities". A healthy scepticism should be developed and nurtured. A "Walk Through" the model with a knowledgeable and critical person may prove very beneficial. "Spin" more than 
one hypothesis and use Darwinian "survival of the fittest". Apply "Ockham's Razor", i.e. "entities are not to be multiplied beyond necessity". More is sometimes less and the dictum, absence of evidence does not necessarily imply evidence of absence, should be remembered.

\subsection{The "Lies, Damned Lies and Statistics" simulation syndrome}

Running any simulation model is always a sampling experiment and all inferences are based on limited and incomplete information. A variety of statistical demons are lurking in any simulation model just waiting to devour the unwary ("lurking" variables, correlation $v$ causation, sampling bias, inadequate sample size, auto-correlation, assumptions of independency, etcetera) Proper experimental design, statistical input analysis and especially output analysis is absolutely imperative.

\subsection{The "Dirty Fingers" simulation syndrome}

The model builder should experience and observe the real system at first hand. An effective model can never be build by only sitting behind a desk or in front of a computer. The manager should not be trusted to explain the system - he may only describe how the system is suppose to work or how he may think it is operating.

"Go ride the train! Go ride the bus!" Robert E Shannon

\subsection{The "Immaculate Model" simulation syndrome}

Simulation is one of the few modelling techniques that allows starting with an aggregated, low level of detail, but nevertheless useful model, and to perform progressive enhancements. This characteristic should be exploited to provide intermediate results on a regular basis, in this way at least keeping the boss or client reasonably content. But "there is a time and place for you to make your mark and show your face" " and deliver a "final" product.

\subsection{The "Client is always Right" simulation syndrome}

The old business adage, "the customer is never wrong", is also true for simulation. The simulation modeller not only has to please the client but often has to tell him/her what he/she needs and where, when, how and why he/she should be pleased. This sometimes implies that the modeller should take the total, complete, full responsibility and, if necessary, force-feed the client.

\subsection{The "Intelligent Computer" simulation syndrome}

Computer hardware and software is a completely indispensable part of simulation modelling and computers are wonderful, fantastic and amazing but they are still not capable of displaying anything even remotely similar to intelligence. Numbers created by a computer

\footnotetext{
${ }^{2}$ William of Ockham (c.1285-c.1349), English philosopher, theologian and political writer

3 "There are three kinds of lies: Lies, damned lies and statistics", Attributed to Benjamin Disraeli by Mark Twain

${ }^{4}$ From "A Time and Place" by Mike and the Mechanics

5 "Le client n'a jamais tort", César Ritz, Swiss hotel proprietor
} 
model should always be viewed with some healthy scientific scepticism and should at least conform to some extent to common sense and "gut feeling".

\subsection{The "All the World's a Stage" simulation syndrome}

Extensive and sophisticated animation capabilities is part of almost all simulation software and may be used very effectively for purposes of marketing, verification and validation. However, a situation where more time is spend on the animation than on the simulation should be avoided since final answers usually come from the simulation and not from the animation.

\subsection{The "The Tim'rous Beastie" simulation syndrome}

Be courageous and try to model in bold strokes, take a big leap of faith once in a while and try to develop some modelling confidence. Be very careful of too much detail. Taking too many small steps may be debilitating : One can only jump over a chasm ! One should not panic or develop the jitters if, for example, a "bug" cannot be found. Rather leave the model alone for a few hours, or if possible a few days, and allow the subconscious to go to work. Too many hours spend on a continuous modelling effort tend to stifle insight and imagination.

\subsection{The "Menacing Miracle" simulation syndrome}

"A miracle, my friend, is an event which creates faith. That is the purpose and nature of miracles"

George Bernard Shaw

It is sometimes rather difficult to convince a client, or the boss, of the advantages of using simulation or the validity of a model but the development of a "quick and dirty" pilot model and some preliminary animation may make all the difference. However, once the client or boss is convinced of the model's value and validity, expect them to expect miracles.

\subsection{The "Man for all Seasons" ${ }^{\text {"8 }}$ simulation syndrome}

There still exists some ignorance about the power and advantages, but also the disadvantages and dangers inherent in simulation modelling. Simulation modelling cannot be used to solve each and every possible problem. Simulation modelling is arguably THE general-purpose technique of all general-purpose techniques but, not every single problem may be equally effectively and efficiently solved by using simulation. Simulation is NOT the universal panacea ! At least seriously consider and investigate a myriad of other possible modelling techniques if and where applicable.

\footnotetext{
${ }^{6}$ From “As You Like It", (1599) act 2, sc. 7, 1.139, by William Shakespeare

${ }^{7}$ From "To a Mouse", (1786) by Robert Burns

8 "A man for all seasons" by Sir Robert Bolt
} 


\subsection{The "Little Boxes"' simulation syndrome}

Simulation modelling requires meticulous attention to detail, in either a "top down" or "bottoms up" fashion and any simulation model consists of numerous sub-models while the final model is usually a model of a "real world" sub-system, which in turn is part of a bigger system. However, an effective model can often not be build by simply piling one piece of "perfect", detailed, sub model on another. Once in a while, similar to an artist, stand back, look at the whole and squint. However, do not stand back too far and risk mistaking ignorance for perspective.

\subsection{The "Pushing the Envelope" simulation syndrome}

Simulation modelling is a relative stable but nevertheless a vibrant and still developing methodology. However, new techniques or approaches do appear every now and again for example the development of optimisation techniques based on evolutionary algorithms specifically aimed at simulation model optimisation [16]. Even "old" approaches are dusted off, expanded and enhanced every once in a while for example the renewed interest in Monte Carlo simulation using spreadsheet software [13]. The simulation modeller should be aware of these developments and try something new or different whenever possible and appropriate.

\subsection{The "Throwing the Baby out with the Bathwater" simulation syndrome}

\section{"A body that don't get started right when he's little, ain't got no show." Mark Twain}

A simulation model may often be developed adopting a variety of modelling approaches and a specific approach may turn out not to be the most efficient halfway through the modelling exercise. At least consider starting all over again rather than try to fix a model started in the "wrong" way.

\subsection{The "Jack in the Box" simulation syndrome}

A simulation model may certainly be used to foster and promote innovation but the model only reflects the modeler's own interpretation of the world and therefore one cannot expect a simulation model to give birth to genuine discovery. Simulation modeling is primarily a "what-if" tool that may be used to test the validity of a stated hypothesis, but the analyst must still pose these hypotheses.

\subsection{The "From One Sandbox to Another" simulation syndrome}

\section{"Give us the tools and we will finish the job" Winston Leonard Spencer Churchill}

One could argue that all simulation languages are "the same" but "some are more equal than others $" 10$. A variety of simulation languages are available and the question of which language

\footnotetext{
9 "Little boxes" by Pete Seeger

10 "All animals are equal but some animals are more equal than others", from “Animal Farm” (1945), ch. 10, by George Orwell
} 
is the most appropriate for a specific simulation project is often posed. It is the author's contention that the "best" language is probably the one that is readily available but above all the one best known to the modeller. A thorough knowledge of the intricacies of a specific language is often worth much more than the possible special features of a relatively unknown language.

\section{CONCLUSION}

"Fine art is that in which the hand, the head, and the heart of man go together" John Ruskin

Many of the preceding "simulation syndromes" may have some conflicting, contradictory, or even contentious elements, i.e. : "Do this, but beware of that", or "Don't do this, unless you can't help it". Therefore, striving for and achieving some kind of balance between conflicting approaches, requirements or objectives may very well be the most important part of the Art of Simulation Modelling and this may be labelled The "Balancing Beam" simulation syndrome.

The process of building a simulation model is often subjected to unrelenting pressures of tight budgets and time constraints and even worse, high expectations for quick and fabulous results. A lack of attention to the Art of Simulation Modelling may easily be the first victim under these circumstances. If at all possible this unfortunate situation should be avoided.

"There is no more sombre enemy of good art than the pram in the hall"

Cyril Connolly

\section{REFERENCES AND ADDITIONAL READING}

[1] Andreou N., 2002, Keynote : Virtual Factory Engineering at General Motors, General Assembly, $4^{\text {th }}$ Annual Simulation Solutions Conference, 7 to 10 April 2002, San Diego, USA.

[2] Balci O. and Ormsby W.F., 2000, Well-defined intended uses : An explicit requirement for accreditation of modelling and simulation applications, Proceedings of the 2000 Winter Simulation Conference.

[3] Banks J., 2001, Panel Discussion : Education for Simulation Practice - Five Perspectives, Proceedings of the 2001 Winter Simulation Conference.

[4] Boyle D., 2000, The Tyranny of Numbers : Why counting can't make us happy, Harper Collins Publishers.

[5] Hartson W., 1997, The Book of Numbers, Metro Publishing Limited.

[6] Kelton W.D., Sadowski R.P. and Sadowski D.A., 2002, Simulation with Arena, McGraw-Hill.

[7] Kirkpatrick B. (editor), 2000, Brewer's Concise Phrase and Fable, Cassell \& Co.

[8] Kruger P.S., 2002, The Art of Simulation Modelling : Advice and Admonishments, Caution and Caveat, $4^{\text {th }}$ Annual Simulation Solutions Conference, 7 to 10 April 2002, San Diego, USA.

[9] Law A.M. and Kelton W.D., 2000, Simulation modelling and analysis, McGraw-Hill.

[10] Pearsall J. and Trumble B. (editors), 1996, The Oxford English Reference Dictionary, Oxford University Press. 
[11] Rohrer M. and Banks J., 1998, Simulation Analysts : Required Skills, IIE Solutions.

[12] Sagan C., 1997, The Demon-Haunted World : Science as a Candle in the Dark, Headline Book Publishing.

[13] Seila A. F, 2002, Spreadsheet Simulation, Proceedings of the 2002 Winter Simulation Conference.

[14] Shannon R.E., 1975, System Simulation : The Art and Science, Prentice-Hall.

[15] Shannon R.E., 1998, Introduction to the Art and Science of Simulation, Proceedings of the 1998 Winter Simulation Conference.

[16] Swisher J.R., Jacobson S H, Hyden P D and Schruben L W, 2000, A Survey of Simulation Optimization Techniques and Procedures, Proceedings of the 2000 Winter Simulation Conference. 
